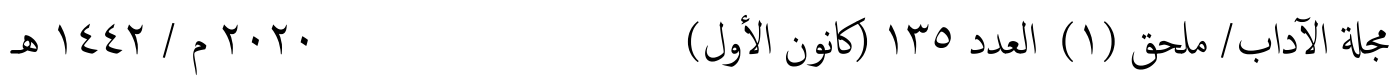

\title{
تكنولوجيا المعلومات والاتصال في التصميم الاخلي
}

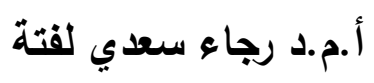

كلية القنون الجميلة/ جامعة بغداد
رهام جاسم حميد

كلية القنون الجميلة/ جامعة بغداد جمياد

rajae.lafta@cofarts.uobaghdad.edu.iq reham.alsallami@gmail.com (مُلَخََّصُ البَحثث)

نظراً للتقدم التقني والتكنولوجي الذي اصبح في الوقت الحالي سبباً رئيس في تغيير

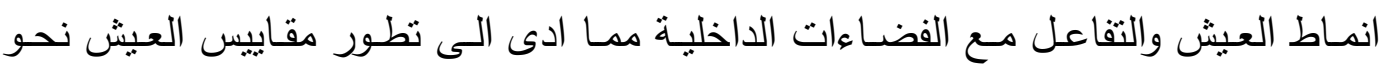

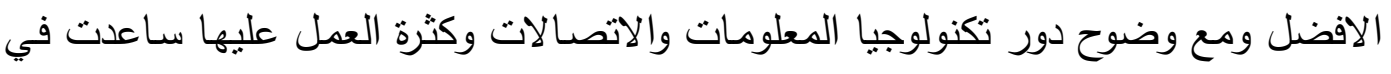
التغلب على العديد من المصاعب فبالتالي ينغي السرعة في العمل لمواكبة هذا الكم الهائل

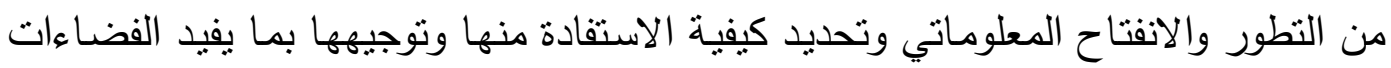
الداخلية والمستخدمين لهذه الفضاءات كذلك لتسهيل عمل المصمم على هذه الفضاءات

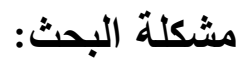

ان جميع الازمنة كانت نظهر فيها تقنيات جديدة تساعد على الارتقاء بمنظومة الفكر

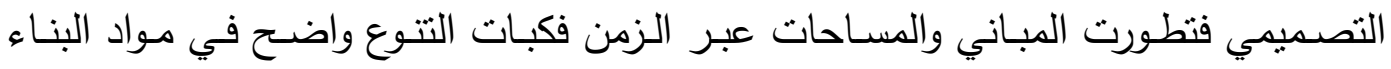
وطرق الانثاء واتساع الفضاءات وتتابعها بأنشكال غير محدودة حيث اصبحت التبن التكنولوجيا

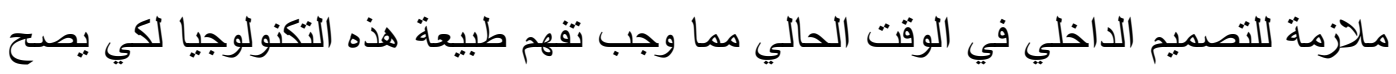
استخدامها والتعامل معها لذا تطرق هذه البحث لدراسة ما وصلت اليه تكنولوجيا المعلومات

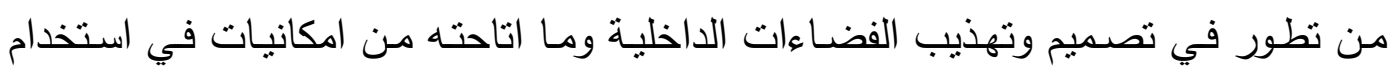
التقنيات الرقمية في كافة صورها مما ادى ذلك لاستحداث أنماط جديدة للفضاءات الداخلية لم تكن موجودة من قبل وسميت هذه الفضاءات عدة تسميات حسب ما تمنلكه من تطور

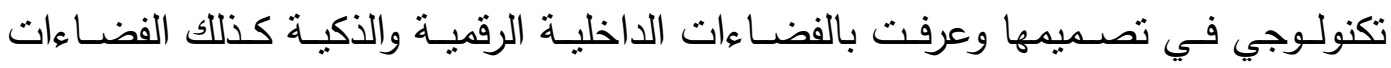

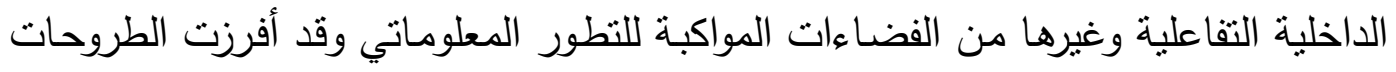

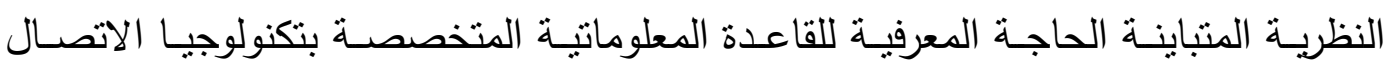
ولغرض مواكبة هذه المعرفة فقد اهتمت الدراسة الحالية بتسليط الضوء على المشكلة البحثية وعلى النحو التالي: الحاجة العلمية لتوضيح طبيعة التكنولوجيا المعلوماتيـة وتفاعلاتها للتصميم في الفضـاءات 
تسليط الضوء على المشاكل التصميمية التي تؤدي الى صعوبات حركية بسبب سوء

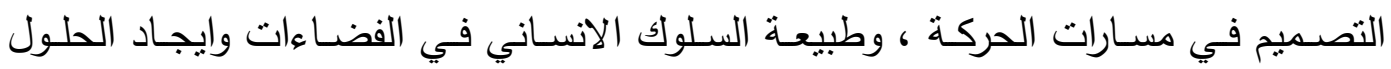
المناسبة لها بأحدث التكنلوجيا هدف البحث

الكثف عن التكنلوجيا الحديثة لمحدات الحركة في تصميم الفضاءات الداخلية للفنادق . حدود البحث

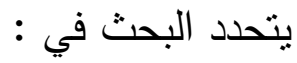
الحدود الموضوعية : التتوع التقني الحركي في تصميم الفضاءات الداخلية الحدود المكـانية : الامارات العربية المتحدة ، امارت دبي ـ فندق برج خليفة الحدود الزمـانية : عام2014- 2015 م . تحديد المصطلحات : التكنولوجيا....تعريفا

ليس هناك للتكنولوجيا تعريف متفق عليه، إذ اختلفت الآراء حول تعريفها وبالتالي حول مفهومها.. فقد ركز بعضهم على الآلات المستخدمة في الإنتاج، في حين أن الآخرين

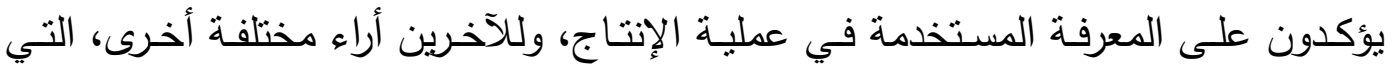
منها. علم الأساليب الفنية-التكنلوجيا، ويعني دراسة الطرق الخاصة بالأعمال اليدوية أو الذهنية

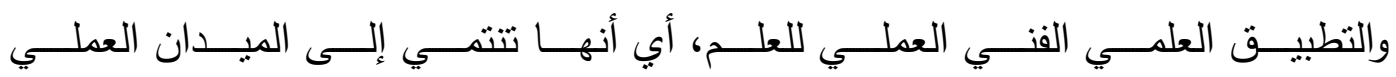

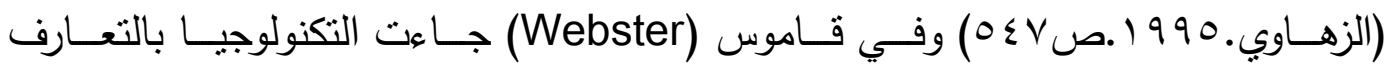

الاتية)(Webster. 1973 2348p)

علم تطبيقات المعرفة، لغرض عملي..(أي علم من العلوم التطبيقية)؛ تطبيقات المعرفـة العلمية لإغراض عملية في فعل معين؛ الطرق الفنية للحصول على إغراض عملية؛ وجميع الوسائل المستخدمة من قبل الناس، لملائمة أهداف الحضارة المادية.

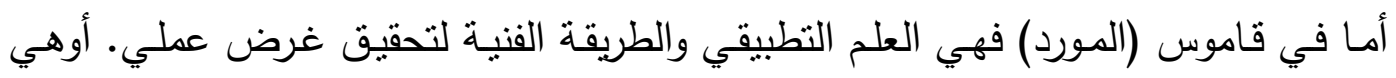

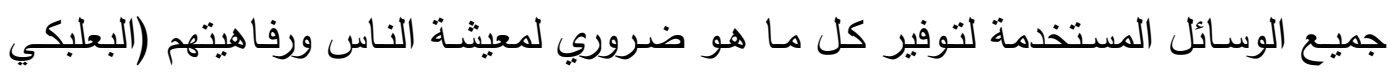

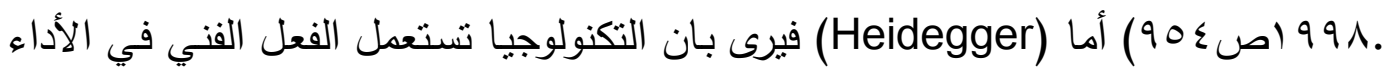

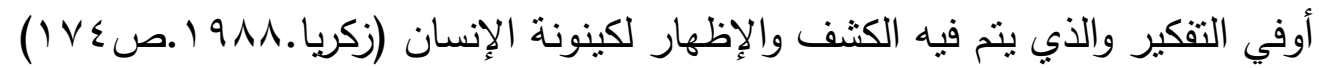


ويعرفها (Ellul) أنهـا " جميـع الطـرق العقلانيـة الفعالـة في كافـة حقـول النشـاطات الإنسانية " أو بعبارة أخرى"هي ليست اقل من المجموعة المنظمة لكافة التقنيات الفردية التي تستخدم لتامين أي هدف" (Susskind .1973. P89) هناللك من ينظر إليها من خلال تكنلوجيا الاستخدام التطبيقي للعلاقات والقوانين والخصـائص الجوهريـة للـواد وتركيباتها، للوصول إلى تشكيلة مادية جديدة قادرة على أداء مهمة معروفة الأبعاد والخصائص مسبقا

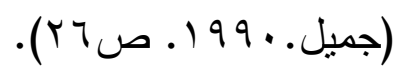
التكنولوجيا.... اصطلاحاً

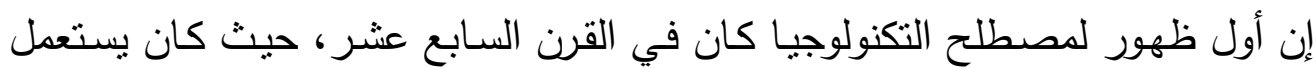

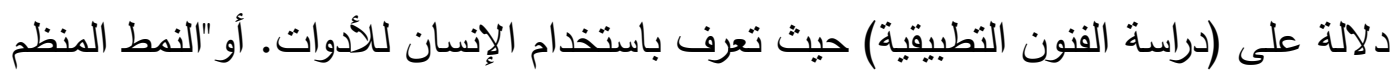

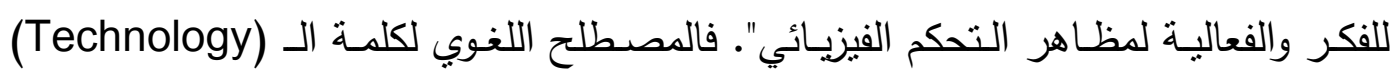

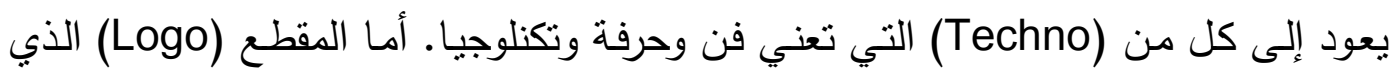

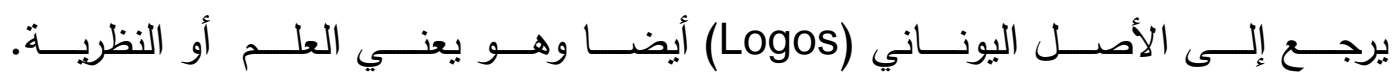
(Webster's.1973. P677) من جزئين هما (Techne+Logo) حيث يمثل الجزء الأول الجانب العملي ويعتمد منطق البق التكنلوجيا ويتصف بكونه يدوي، موضوعي، فردي، واقعي، ومادي ملموس. في حين يمثل

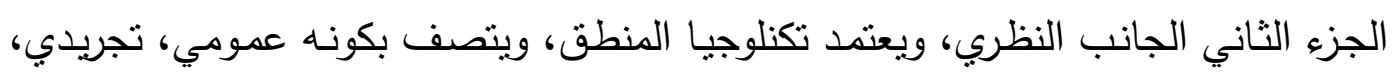

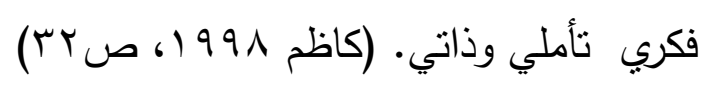
وقد جاء في مصدر آخر أن التكنولوجيا تعرف من أصلها الإغريقي (Technikan)

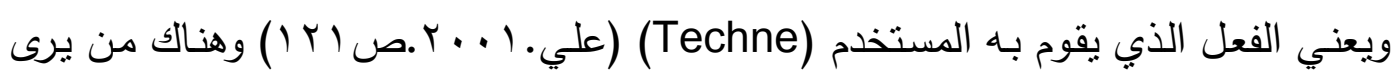
انه نظرا إلى التركيب اللفظي الخاص لكلمة التكنولوجيا الذي ينتهي نهاية تدل على (العلم) كما هي الحال في الجيولوجيا، فان بعضهم يفضل استخدام لفظ التكنولوجيا بمعنى (علم) التطبيقات العملية، أبي دراستها المنظمة (Frampton.1995. p.151) وجاء في مصدر آخر إن (التكنولوجيا) في أصلها كلمة مشتقة من الإغريقية، مقطعها

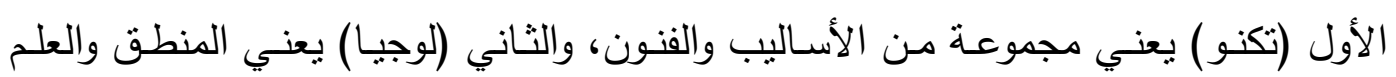

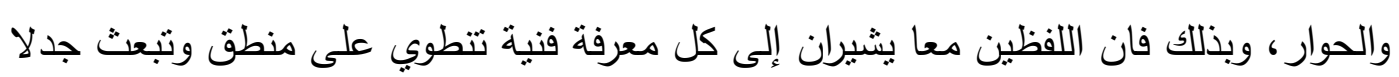

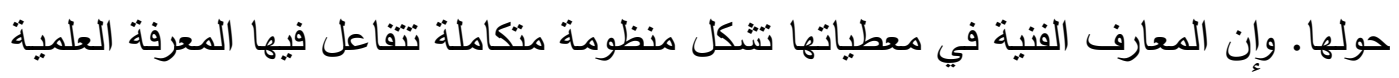

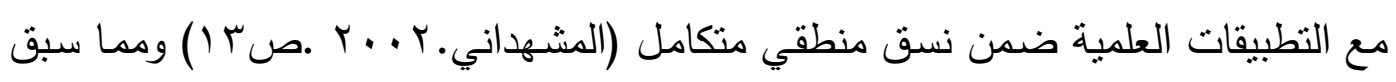

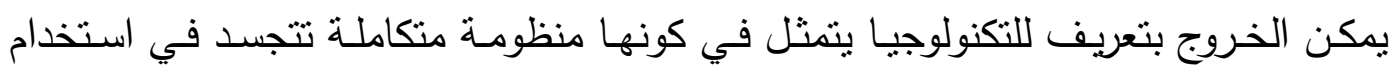

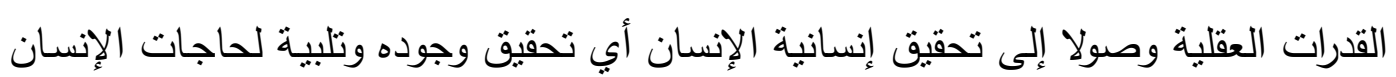
المادية والروحية سعيا وراء تحقيق الكمال. 
ومن هذا التعريف يتطرق البحث لأهم المفردات المعرفية المتعلقة بتعريف التكنولوجيا، بدءا من تعريف النظام وكيف يمكن أن يعمل نظام التكنولوجيا المعقد. الفصل الثاني

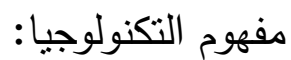

لمصطلح التكنولوجيا استخدام واسـع اليوم، وهو ليس إلا انعكاسـاً لأهميـة التكنولوجيا

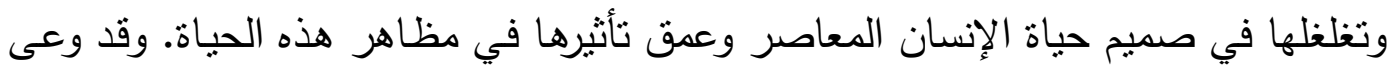

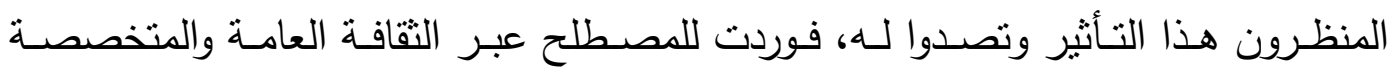
تعريفات متتوعة تربط التكنولوجيا بأبعاد مختلفة ( العلم والفن والفكر والأخلاق)، ونسبت إلهورت إليها

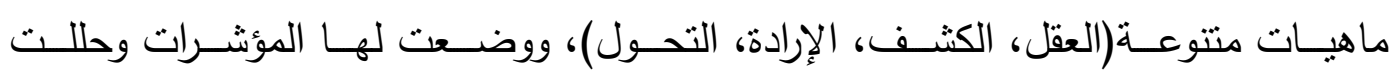

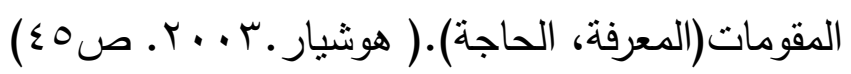

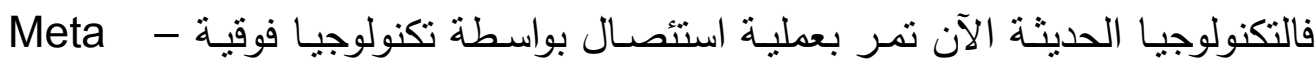
Technology

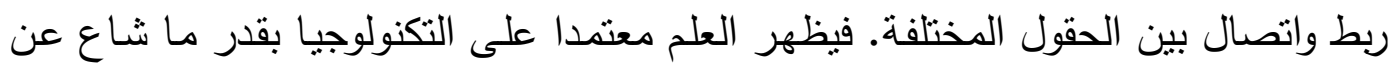

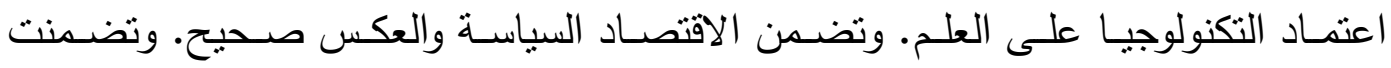
السياسة الدين والعكس صحيح. وتضمن الفن الاقتصاد والعكس صحيح. فما يتم خلقه الآن يمكن ان بسمى ثقافة افتراضية عامة ، ويتم ذلك إلى حد كبير خلال التكنولوجيا.

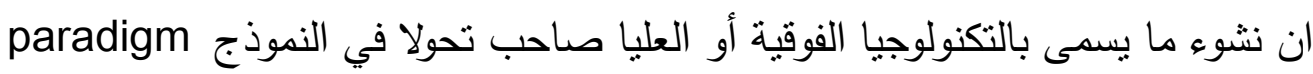
shift

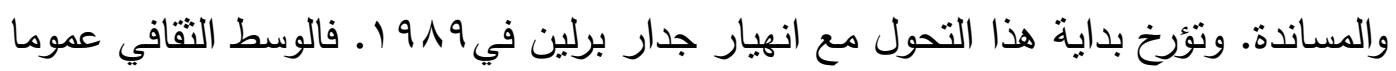

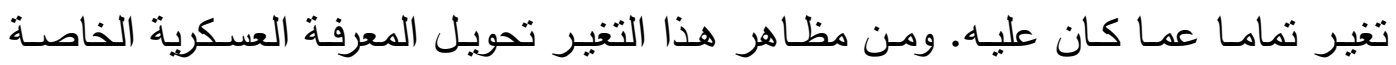

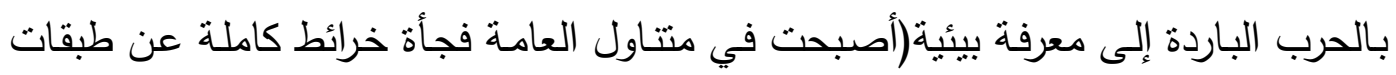
المحيط والحرارة الكونية وتغيرات مستوى المحيط، بعد أن كانت هذه كلها حصرا على خلى خبراء

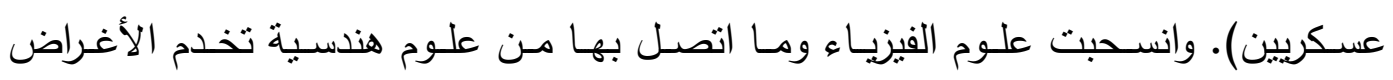

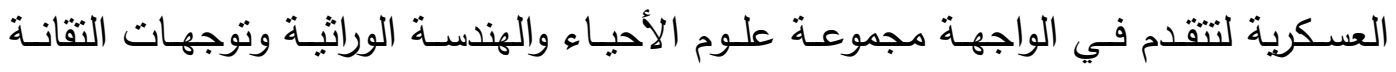

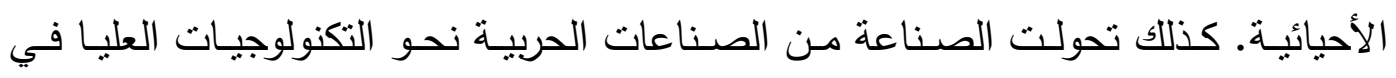

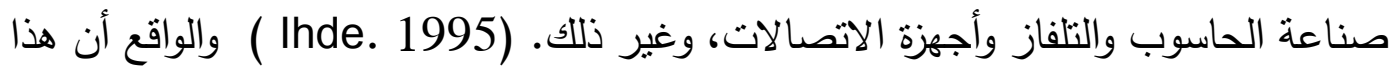
التحول المرصود نسبي وجزئي ، فما زالت الصناعات الحربية دافعاً أساسياً من دوافع التطور

في Ernesto Mayz Vallenilla

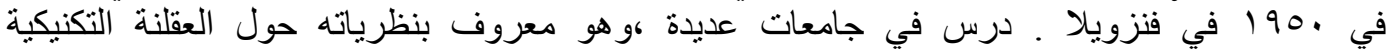

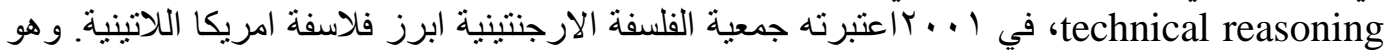

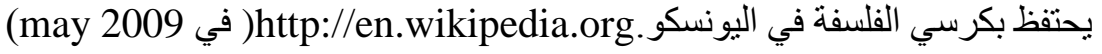


التكنولوجي. ويمكن القول إن هناك علاقة طردية بينهما. وتتضمن التكنولوجيا في التصميم

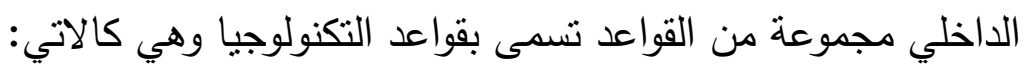

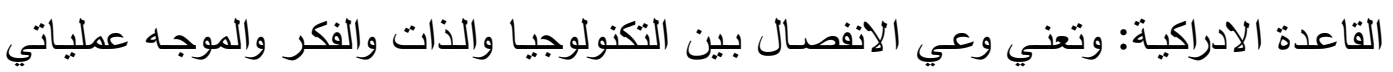
والدوافع الداخلية للتغيير • p48. 1979. Jean ) ا. القاعدة المعلوماتية: وتعني المحددات الثقافية والبحوث اضافة الى كل ما يتعلق بآليات انتخاب الحلول وتحفيز الصور الذهنية. r. القاعدة اللغوية: وتتضمن خصوصية لغة التكنولوجيا وتداولاتها.

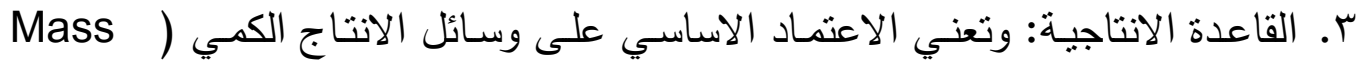
(Production

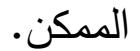
القاعـدة التنفيذيـة: وتحتــوي علـى ثلاتــة انــواع رئيسـية هـي الاســلوب الحرفـي والاسلوب المرشد (The Craftsmanship) (عاطف. (The Industrialized) تأثير المجتمع المعلوماتي على البيئة العمرانية العربية:

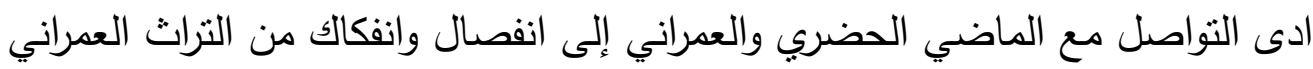

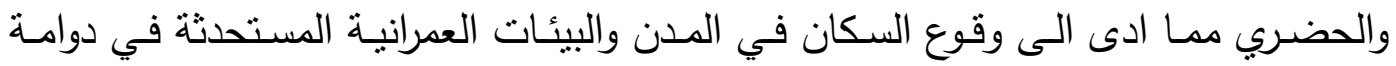
صيانة وحفظ الهويـة المعماريـة والعمرانيـة مـع محـاولاتهم للتكيف بـين البيئـات العمرانيـة المستحدثة وطرقهم وعاداتهم وأساليبهم الحضارية والاجتماعية، وإن سلسلة التحول العمراني

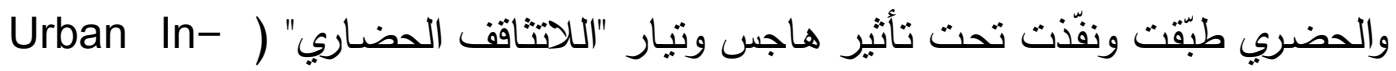
(acculturation

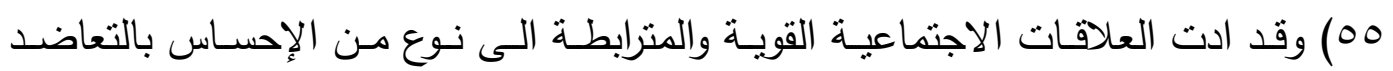

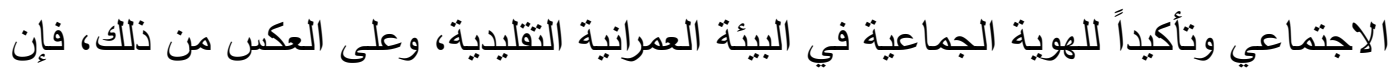

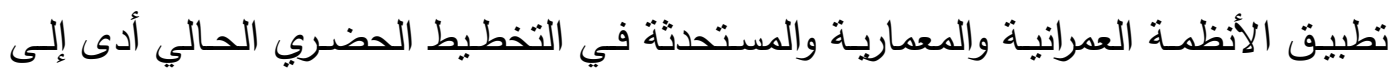

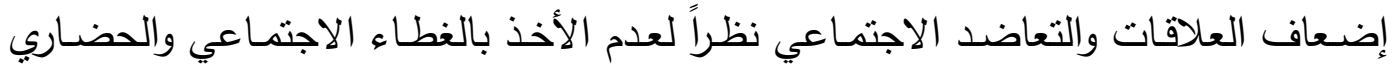

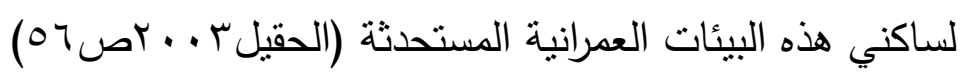
حافظت البيئة العربية الإسلامية على الخصائص والمبادئ الصافية ، فالحضارة العربية

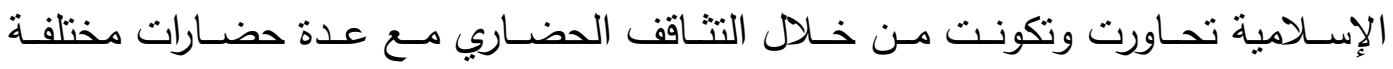
كالإغريقية والرومانية والفارسية والهندية، وفي بدايات تلك الحقبة من التاريخ الإنساني لم

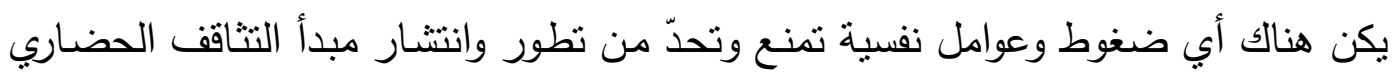

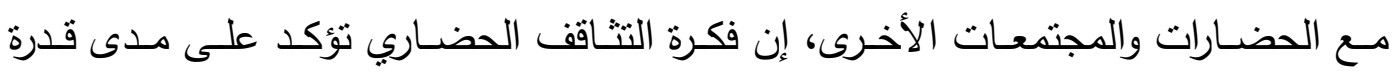


واستطاعة الثـعوب على اختزال وهضم الأفكار والطروحات الأجنبية ووضعها في المكان

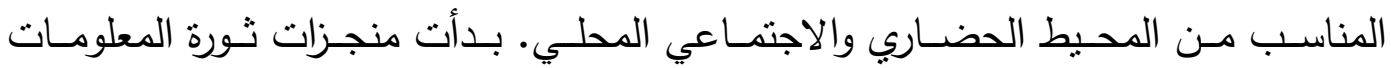

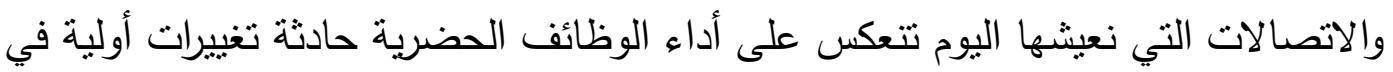

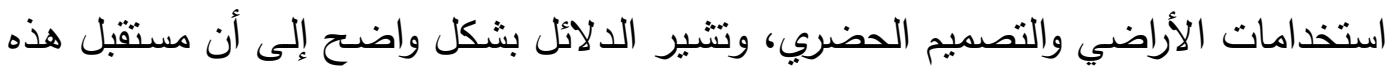

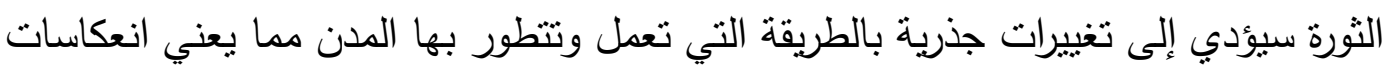
هامة على التصميم واستخدامات الأراضي في المدن(Komninos2002.p22) فضاءات عمارة الثورة الصناعية وإلحداثة

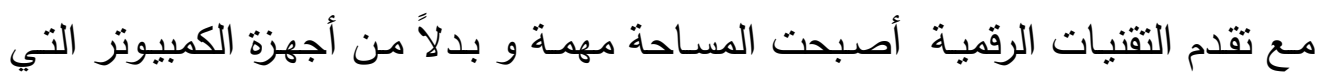

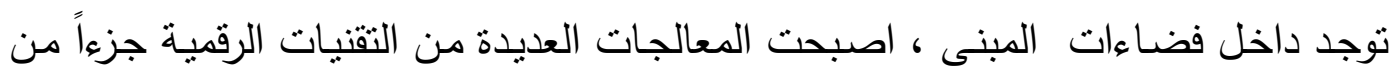
الفضاء إمّا موجودة داخل جدران المبانياو ضمن مساحة الفضاء وبالاتنقال الى عمارة عصر الثورة الصناعية التي تعد نقلة في خصائص الفضـاءات الداخلية ويعود ذلك للخول مواد جديدة كالدديد الصب والفولاذ والذي بدوره اثر على النظام الانشائي في المباني ـ فاعتمدت

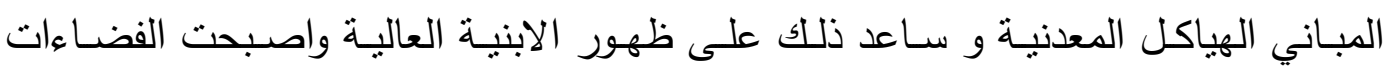

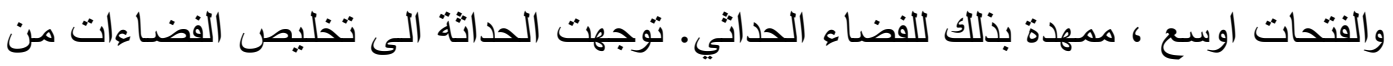
كل ما هو زائد عن الحاجة ، فاتجهت الى الافراط في تبسيط مكونات الفضاء والاقتصار على ما هو ضروري فقط من ناحية وظيفية (Hassan.2007 p.838)

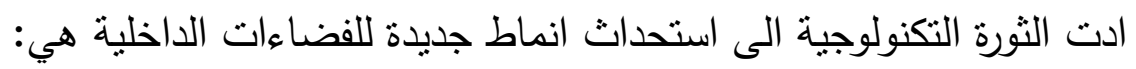
اولاً: الفضاء الرقمي ( Digitals space): يشير الفضاء الرقمي الى المجتمع المتصل، الذي يجمع البنية التحتية للاتصالات ذات التهات

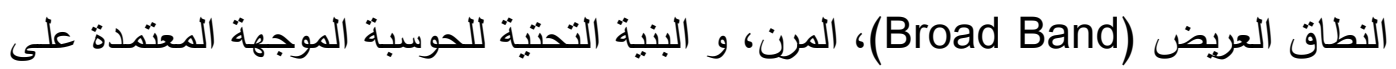

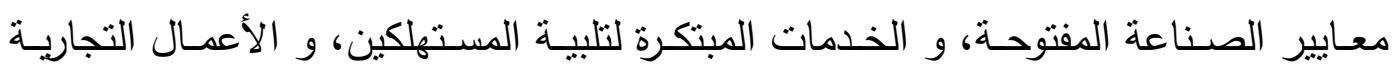

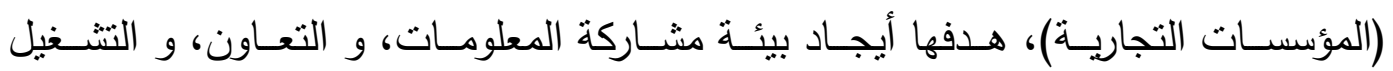

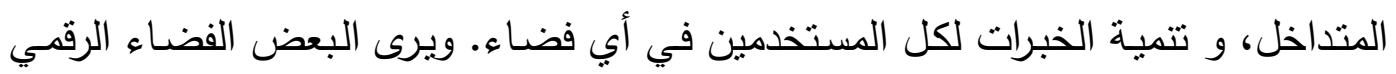

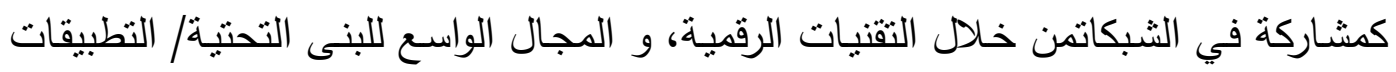
( p445.2009. Yovanof) إن الفضـاء الرقمي يمكن أن يوجد لجميع الأنشطة الحياتيـة والاستغناء عن الفضــاء

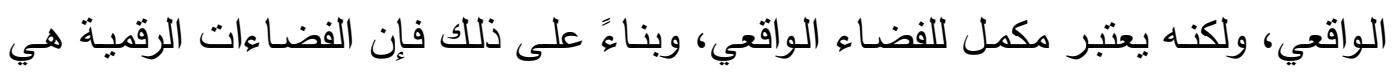
ارتباط بين الفضـاء الرقمي الالكتروني والفضـاء الواقعي، وتظهر تلكئك العلاقة من خـاد

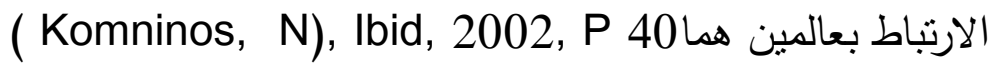


العالم الحقيقي: الذي يتمنل في الفضاءات الواقعية داخل المباني الحقيقية، وتحوي تلك الفضاءات السكن والعمل والانتقال والخدمات والتزفيه وخلافه، كما يتميز ذللك العالم الحقيقي

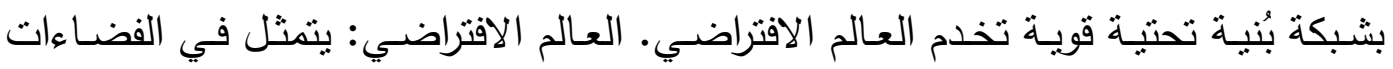

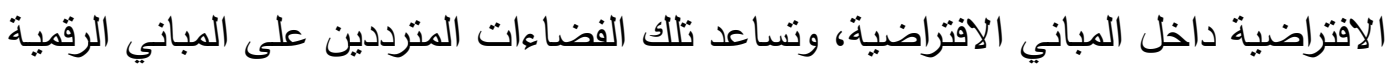
- من خلال مواقعهم في المباني الواقعية على ممارسة الأنثطة الحضرية المختلفة.

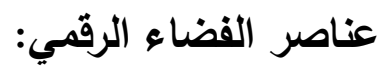

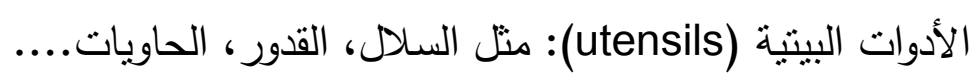
الأجهزة (apparatus): مثل حاويـات الصباغة أفران الطابوق، حاويات معينة لعمليات الفيات

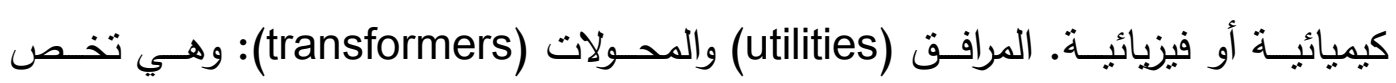

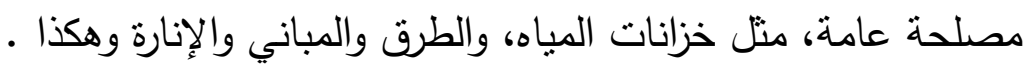

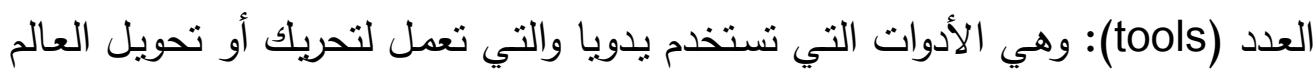

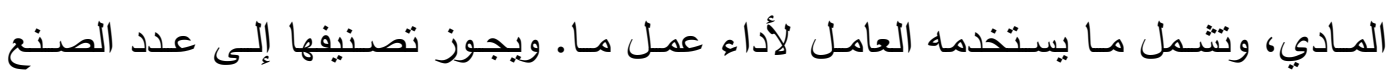

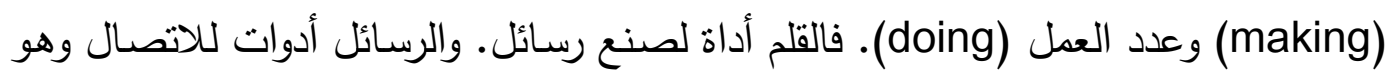
نوع من العمل. المكائن (machines): وهي آلات لا تحتاج استخدام الطاقة البشرية لوجود مصدر

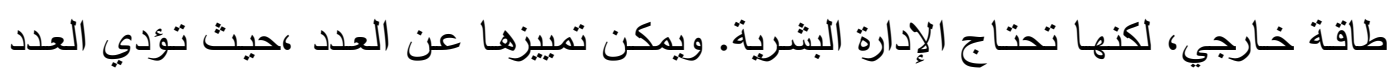

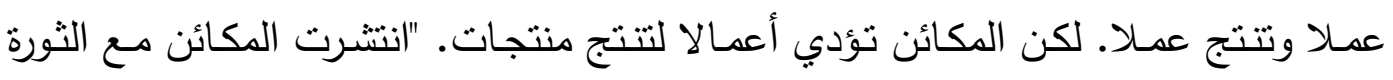
الصناعية، مع ذللك فكائن مثل طواحين الهواء هي اقدم بكثير (wikipedia2009)

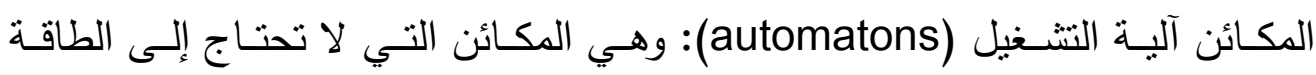

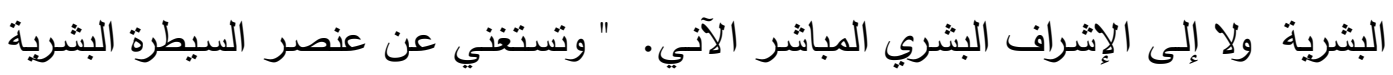

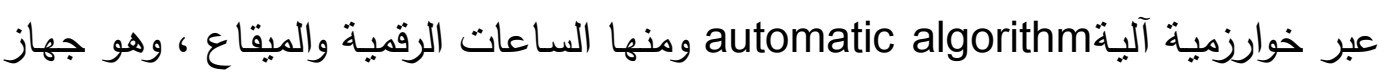
يستخدم لضبط ايقاع نبضات القلب ويوضع في صدور مرضى القلب(wikipedia2009)"

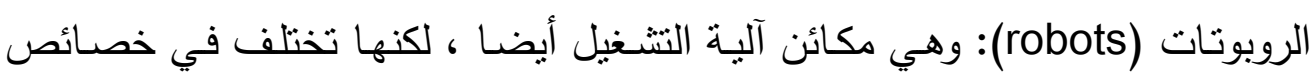
معينة ، خاصة كونها تصنع لتقليد العمل البشري اليدوي، او لتقليد كائنات حية عموما. ثانياً: الفضاء الأكي( Intelligent space): انبثق مفهوم الفضـاءات الذكية (Intelligent space) من تقاطع (التقاء) العناصر

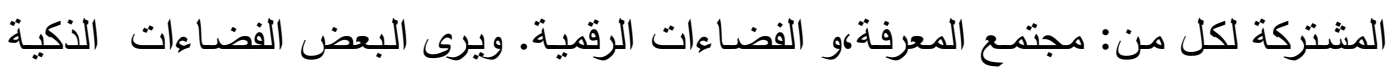

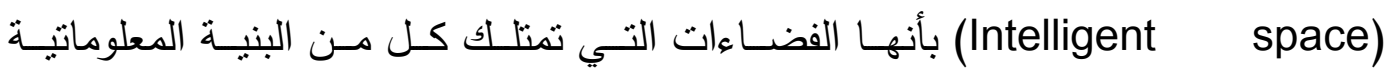
لتكنولوجيـا المعلومـات، و أحدث التقنيـات في تكنولوجيـ (Information structure)

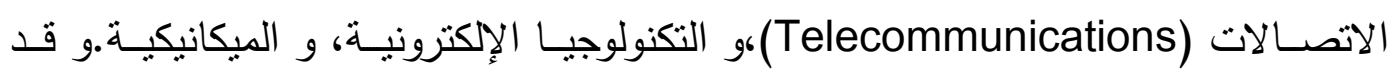


يتطلب الثروع بالفضـاءات الذكية (Intelligent space) بذل جهود كبيرة في استخدام تكنولوجيا المعلومات، لتحويل الحياة و العمل في أطار المنطقة، بطرق مبدعة و ذكية، بدلا

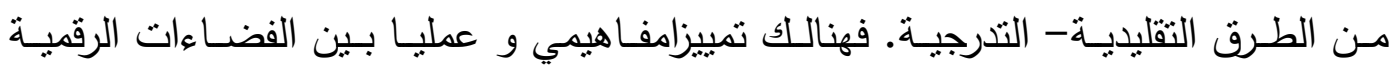

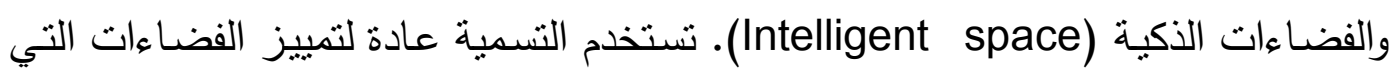
تمتلك القدرة لدعم التعلم، و التطور التكنولوجي، و فعلالابتكار، وبهذا المعنى فأن كل فضاء

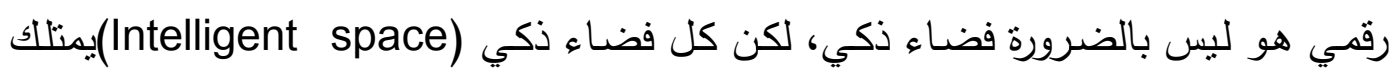
مكونـات رقميـة. إذ ان كل من المفهومين يختلف، من حيث الربط بين الفضـاء الواقعي لوني

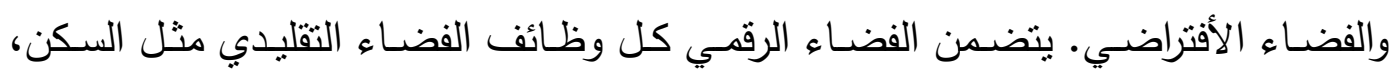

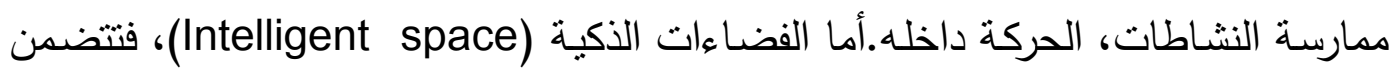

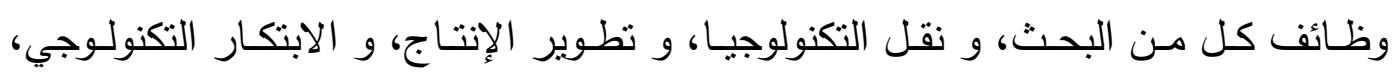
وموطن الصناعات المبنكرة(Komninos. 2009)

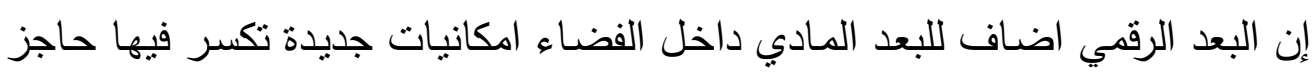

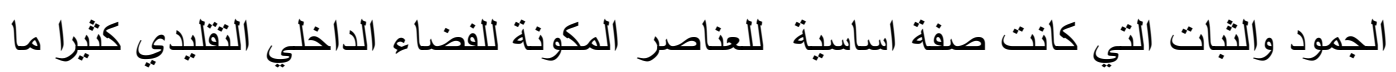

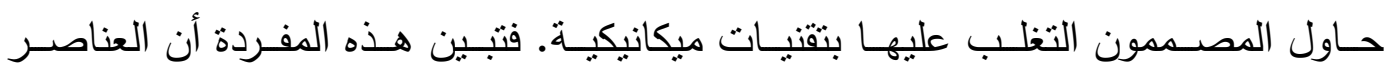

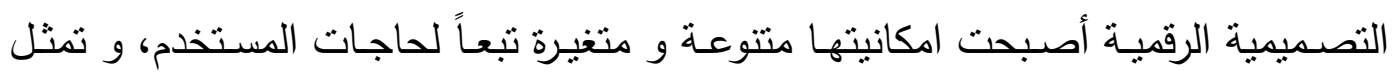

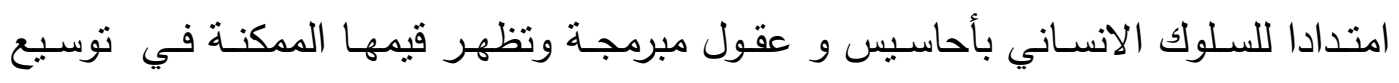

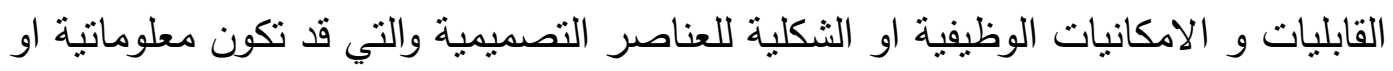

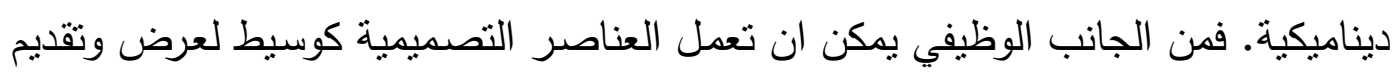

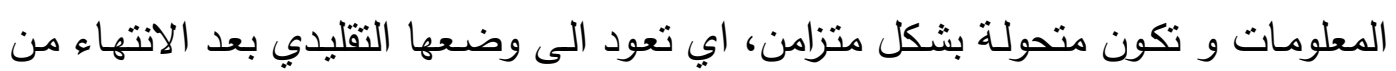

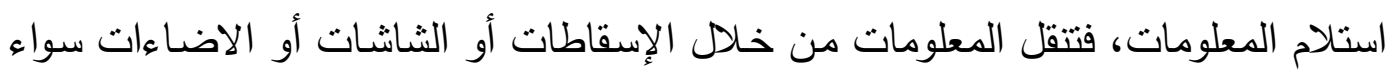

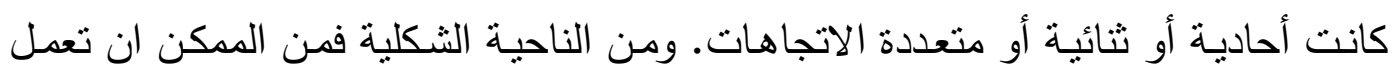

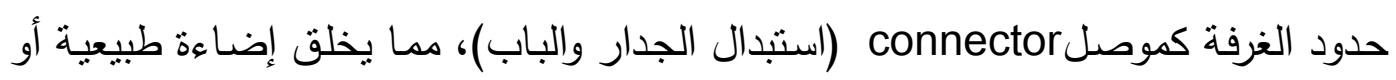

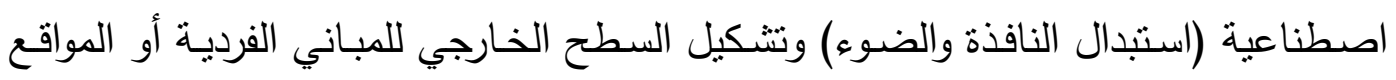

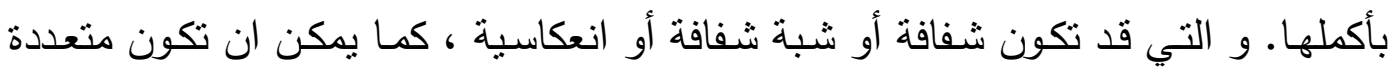

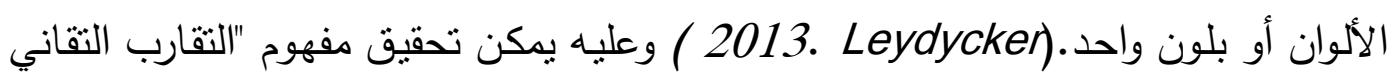
Technological Convergence مختلفا، يحمل صفات كل منها على حدة، ويكون بذات الوقت متفرداً تنماماً في صفاته، بما

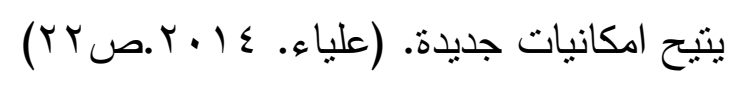


لقد انبثق مفهوم الفضـاء الذكي (Intelligent space)، كتطبيق سـاكن (Static)

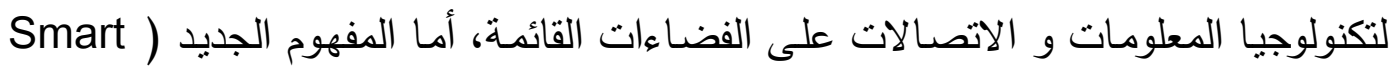

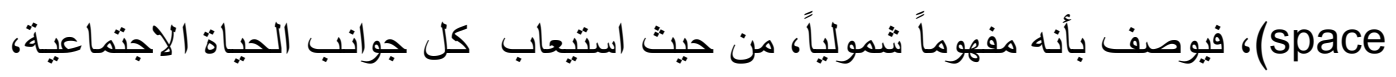

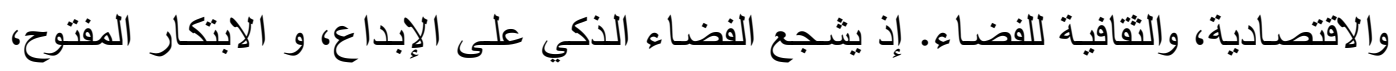

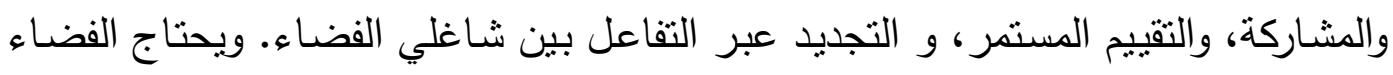

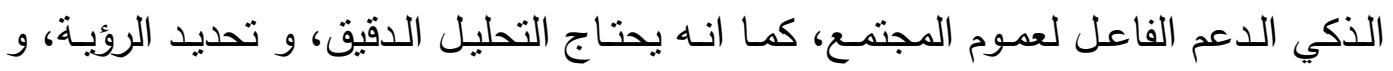

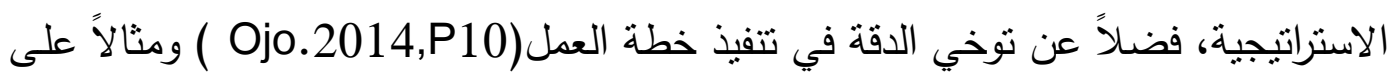
الفضـاءات الذكية مبنى (The Edge) في امستردام اذ يعتبر أذكى مبنى في العالموأكثر

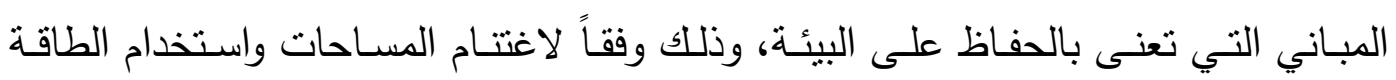
الثمسية التقليدية وأسلوب العمل في تلاك المكاتب.

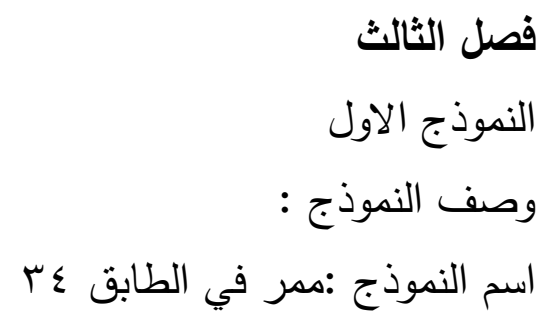

شكل الفضاء : أولاًَ- المحددات الافقية: يكون شكل المسقط الافقي للفضاء الداخلي للممر أقرب ما يكون للثكل المستطيل ذي انفراج في بدايته وكما هو واضح في الثكل (

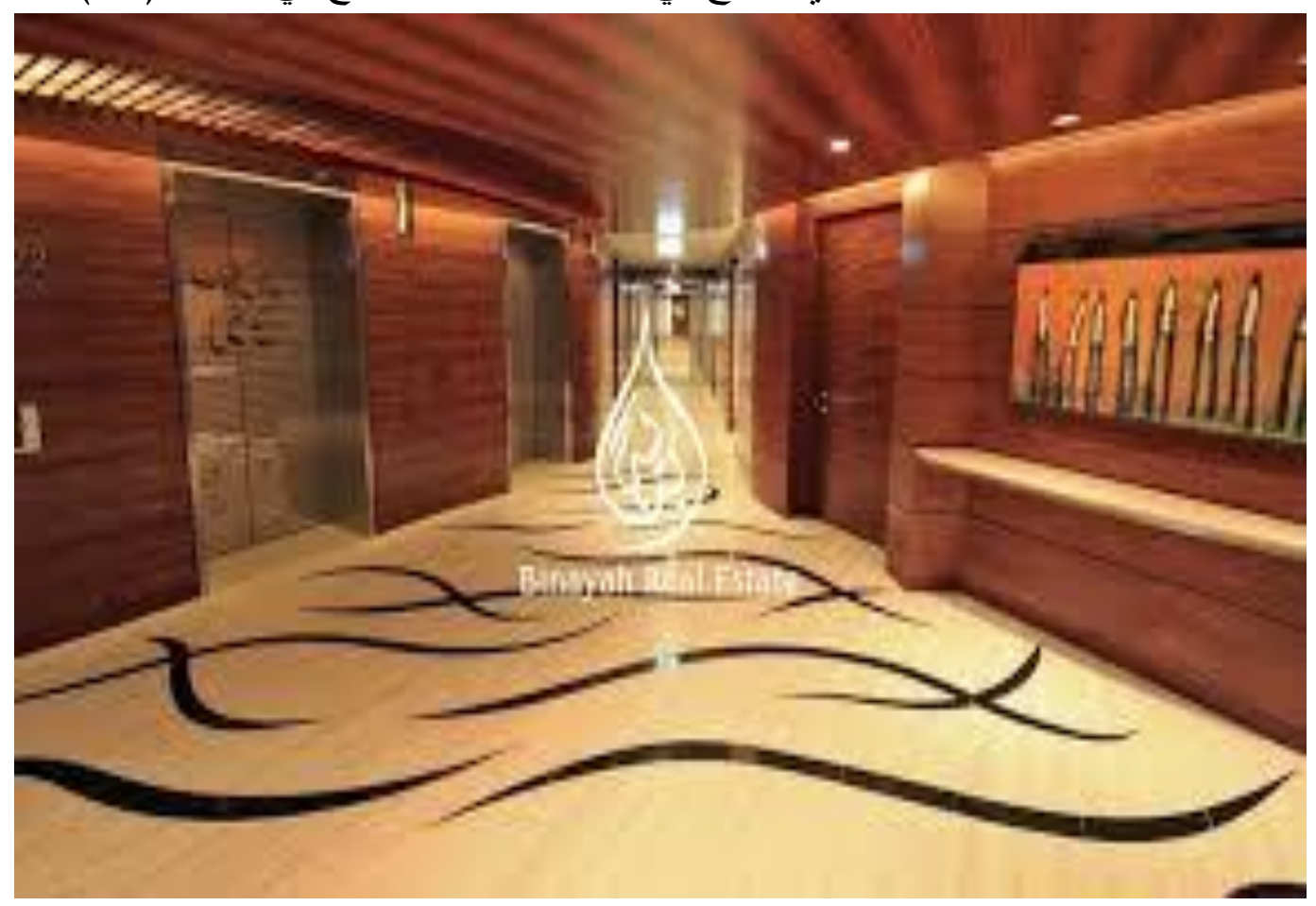

شكل (1) يوضح الخطوط المنحية المستخدمة في الممر 
الارضية : من الرخام الابيض الذي يحتوي على خطوط انسيابية .

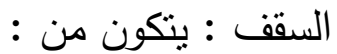

سقف ثانوي مصمم من خامة (Mineral Fiber Armstrong Ceilings ) وهو عبارة عن الواح ذي شكل الخشب متضـنة وحدات الاضـاءة عليها لفتحات التكييف ومتحسسـات

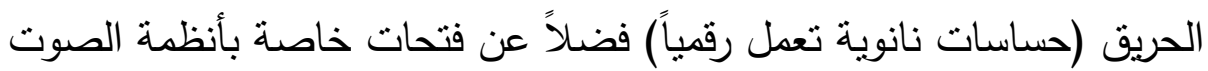
وحدات الاضاءة الرئيسة في الفضاء Spot light من نوع الـ LED متغير الثندة

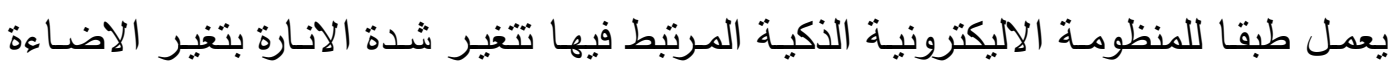

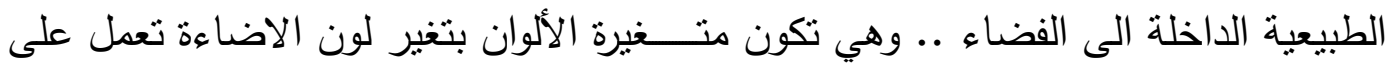
وفق نظم ذكية من طريق اجزة الـ IPAD من خلال شبكة الـ wifi الجدران : تم تغليف الجدران بالواح من الخشب على طول المر الاعمدة : غير ظاهرة تكون متضمنة مع الانشاء المعماري للفضاء الفتحات : تحتوي على عدة فتحات خاصة بالمصاعد الكهربائية التحليل

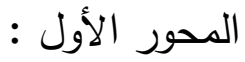
العناصر السطحية : - الاول: في اثتـاء ملاحظـة المخطط الافقي رأينـا أن الفضــاء الداخلي للمـر هو شكل شبه مستطيل، وجاء تصميم الارضية من خامة الرخام الابيض متضمنة خطوط سوداء اللون مشعة للضوء حين انعكاس الضوء عليها وهي تقود الاشخاص الداخلين للفضاء من البداية

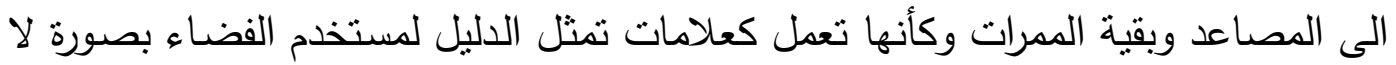

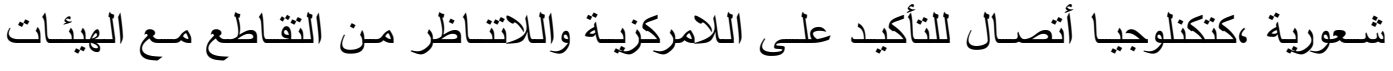

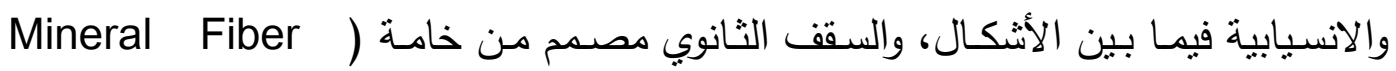
) وهو عبارة عن الواح ذات ملمس خشبي منضمنة وحدات الاضاءة عليها ومؤكدة من خلال الاضـاءة ذات الالوان المتغيرة كتكنلوجيا لتحقيق الاثارقفي

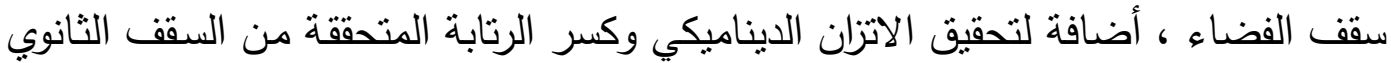

كما هو واضح في الثكل (1)

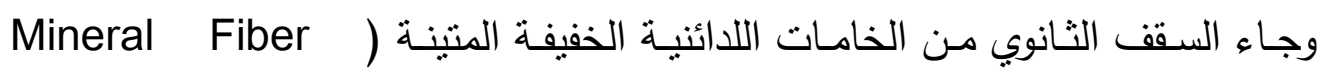
( Armstrong Ceilings التشكيل ولها سطوح ناعمة تعطي الاحساس بالنقاوة لتحقيق الوظيفة التي يؤديها الفضـاء

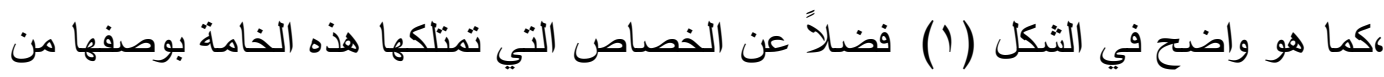

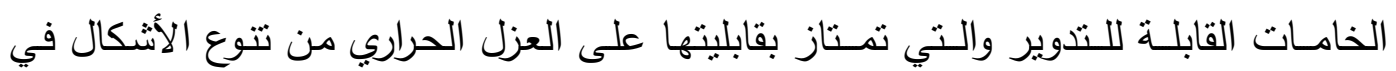


الفضاء التصميمي تحققت تتوعات اتجاهية نتج عنها إيهاماً بالحركة حقق وظيفة جمالية

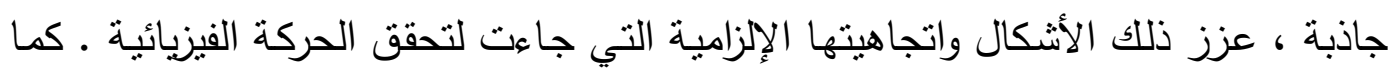
كان للتغيير الذي ظهر في الصورة المسنطيلة نسبةً إلى الفضاء الذي ظهر بأبعاد مستطيلة

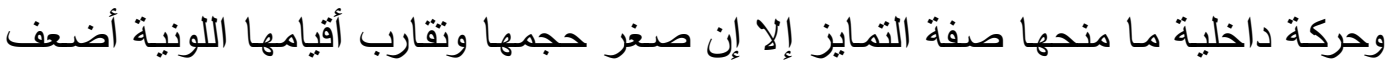

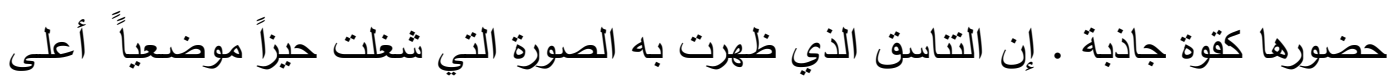
يمين الفضـاء التصميمي حقق لها خصوصية ضـعيفة بسبب تقارب الالون مـع الفضـاء الموضوعة به شكل رقم (1) و كان لطبيعة العناصر البنائية التي اعتمدت على الاثكال ذات الحركة الوهمية التي

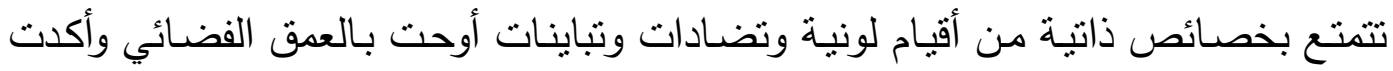

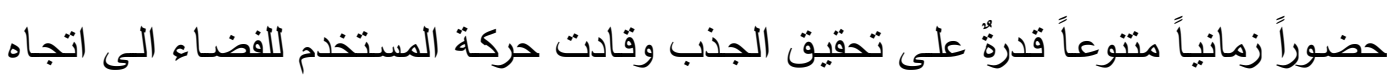

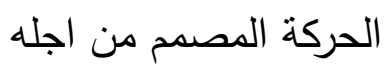

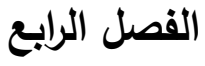
النتائج

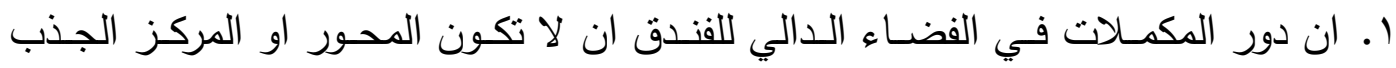

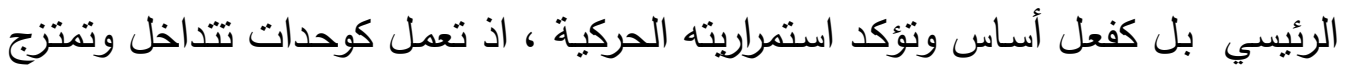

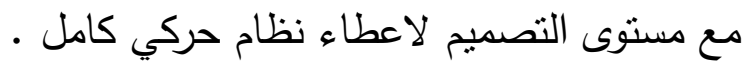
r. ان استعمال اللون كنظام للترميز في مناطق الحركة مرغوب من اجل تصميم نقاط مثيرة للاهتمام وخلق وتيرة متغيرة للمستخدمين اثتاء التحرك في فضاءات الفندق .

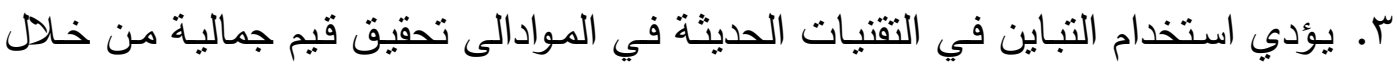
الاختلاف في المجال المرئي مما يشد المتحركة الى النقطة التي يريدها من لال التقنيات

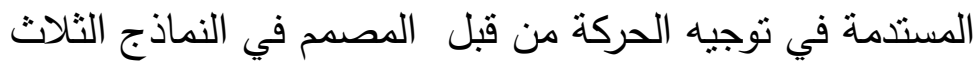

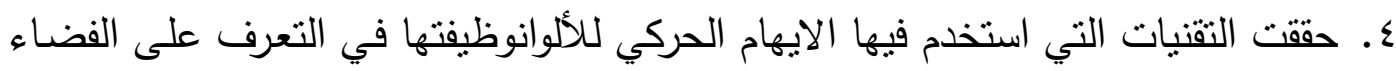

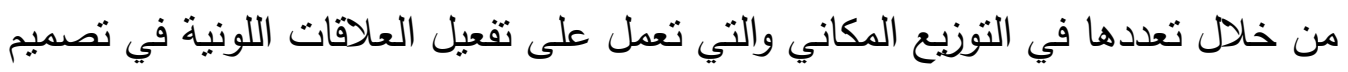
الفضاء مما يؤثر إيجاباً في المستوى الاظهاري التصميمي للفضاء التهاء الداخلي للفندق .

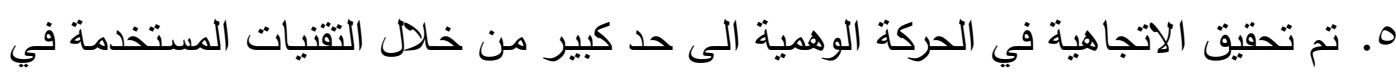

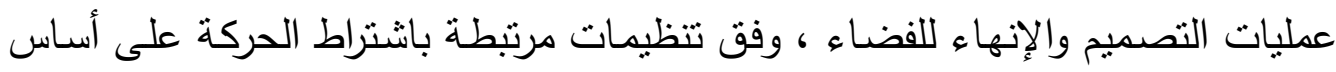

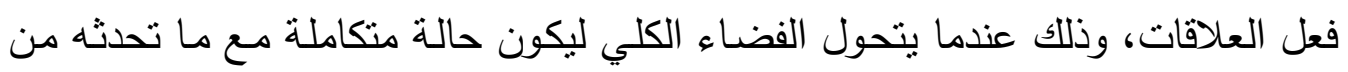
مؤثر على هيئة الادراك وبما يتوافق مع نظام حركته . 


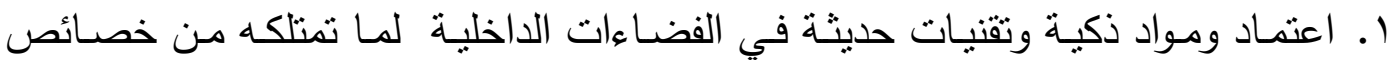
وظيفية وجمالية لتحقيق الأداء الوظيفي.

r. أستعمال المواد الثقليدية بأساليب تكنلوجيا حديثة لتحقيق الاداه التجاهية الحركية في في اثثاء طرق المعالجة كأسلوب تشكيل الخامة الغير مألوفة التي تساعد على جذب النتباد النباه العين

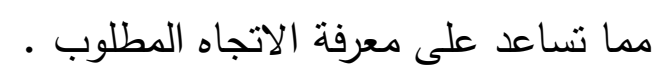

r. اعتمدت الاساليب التكنلوجيا الحديثة للإضـاءة على وحدات الانارة المتصلة بالمنظومات

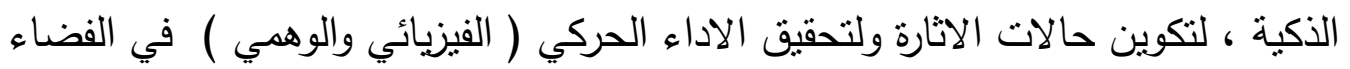

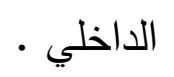

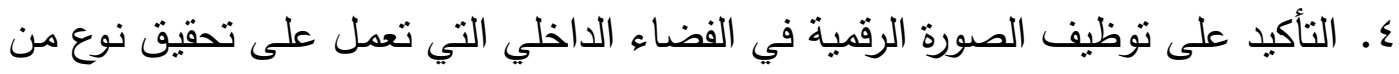

$$
\begin{aligned}
& \text { البعد الحركي في الفضاءات اضافة الى الاستدامة الثكلية مع البيئة . } \\
& \text { بعد الانتهاء من إظهار نتائج البحث يوصي الباحث بما يأتي : }
\end{aligned}
$$

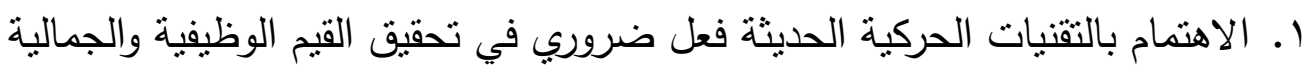

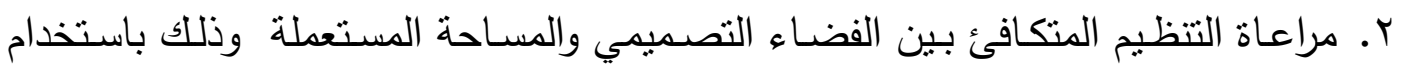

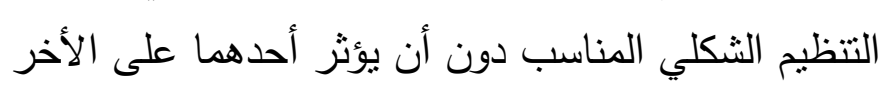

المقترحات

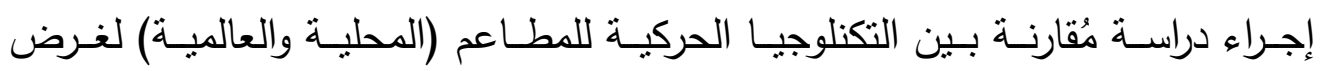

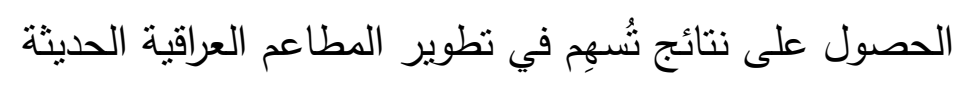

\section{references}

Addington, M., \& Schodek, D. ,Smart Materials and New Technologies. British Library,2005.

Ali, Khalil and Imam, Muhammad, Technology and Communication System, Iraqi Journal of Architecture, First Issue, Department of Architecture, University of Technology, 2001.

Alia Ahmed Rashid, Intellectual and Formal Data of Digital Architecture and its Sustainability, PhD Thesis, University of Baghdad - College of Engineering, 2014.

Al-Mashhadani, Akram Abdul-Razzaq, Arabs in the face of the technical challenge and its social implications, the cultural situation, No. 39, seventh year, House of General Cultural Affairs, Baghdad, 2002.

Al-Zahawi, Omar Sami, Form and Environment - An Ecological Study of Architecture, MA thesis, College of Engineering, Baghdad University, 1995 Atef Al-Suhairi, Building Construction, Arab Awakening Library, Kanaan Press, Baghdad, Iraq, 1991.

Baalbaki, Mounir, Al-Mawred, English-Arabic Dictionary, Dar Al-Alam for Millions, Beirut, Lebanon, 1998,

Bullivant, L., 4dspace: Interactive Architecture. London: Wiley Academy, 2005. 


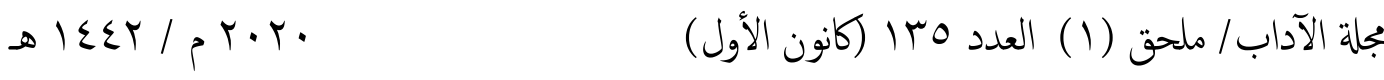

Calderon, C., Interactive architecture design. Harvard Graduate School of Design, 2009.

DonIhde, Philosophy of Technology: 1975-1995, in: Techne, Vol.1, State University of New York at Stony Brook, Fall 1995.

Fox, M., \& Kemp, M. Interactive Architecture. new York: Princeton architectural Press, 2009.

Hassan , N., Architectural Space From Modernism to Deconstruction: A Critical Overview. Journal of Engineering Sciences, Assiut University, 2007.

Jameel, Adnan Abdul-Karim, Technological Theory and Technological History, Small Encyclopedia 344, House of Public Cultural Affairs, Baghdad, 1990

Jean Ladariere, the Challenge Presented to Culture by science and Technology, The Unesco press, 1979.

Kazem, Prof. Mazen Abdel Hamid, Engineering and Technology Competition or Integration, Journal of Engineering, No. 2, Al-Nahrain University, October 1998

Komninos, N., "Intelligent Cities, Innovation, Knowledge System and Digital Spaces", London, Spon, 2002.

Komninos, N., \& Sefertzi, E. "Intelligent cities: R\&D off shoring, Web 2.0 product development and globalization of innovation systems", Paper presented at the Second Knowledge Cities Summit, 2009.

Kurtich, J., \& Eakin, G., Interior Architecture. New York: Van Nostrand Reinhold, 1993.

Leydycker, S., Designing Interior Architecture. Germany,2013

Ojo, Adegboyega; Curry, Edward and Janowski, Tomasz. "Designing Smart City Initiative", Twenty Second European Conference on Information Systems, Tel Aviv 2014.

Ritter, A. Smart Materialsl in architecture, interior architecture and design. Germany,2007.

Schnädelbach, H. (2010). Adaptive Architecture - A Conceptual Framework. In F. E. Jens Geelhaar, MediaCity Interaction of Architecture, Media and Social Phenomena. Bauhaus-Universität Weimar,2010.

Susskind, Charles, Understanding technology, The Johns Hopkins University, Press LTD, London, 1973

Webster's new collegiate dictionary, G. and C. Merrsiam co., First printing, U.S.A., 1973

Yovanof, G. S., \& Hazapis, G. N. "An architectural framework and enabling wireless technologies for digital cities \& intelligent urban environments". Wireless Personal Communications, 49(3), (2009.

Zook, M. A., \& Graham, M. "Mapping digiplace: Geocoded Internet data and the representation of place". Environment and Planning B: Planning and Design, 34(3), (2007. 


\section{Information and communication technology in interior design}

\section{ABSTRACT}

In view of the technical and technological progress that has become at the present time a major reason for changing lifestyles and interacting with internal spaces, which led to the development of standards of living for the better, and with the clarity of the role of information and communications technology and the abundance of work on them, it helped to overcome many difficulties, thus changing the speed in work to keep pace with this. The vast amount of development and openness of information and determining how to benefit from it and direct it in a way that benefits the internal spaces and the users of these spaces as well to facilitate the work of the designer on these spaces 